\title{
On the Cover of this Issue: A Robust Finite Element-based Filter for Digital Image and Volume Correlation Displacement Data by T.H. Becker and T.J. Marrow
}

Published online: 28 June 2021

(c) Society for Experimental Mechanics 2021

(a)
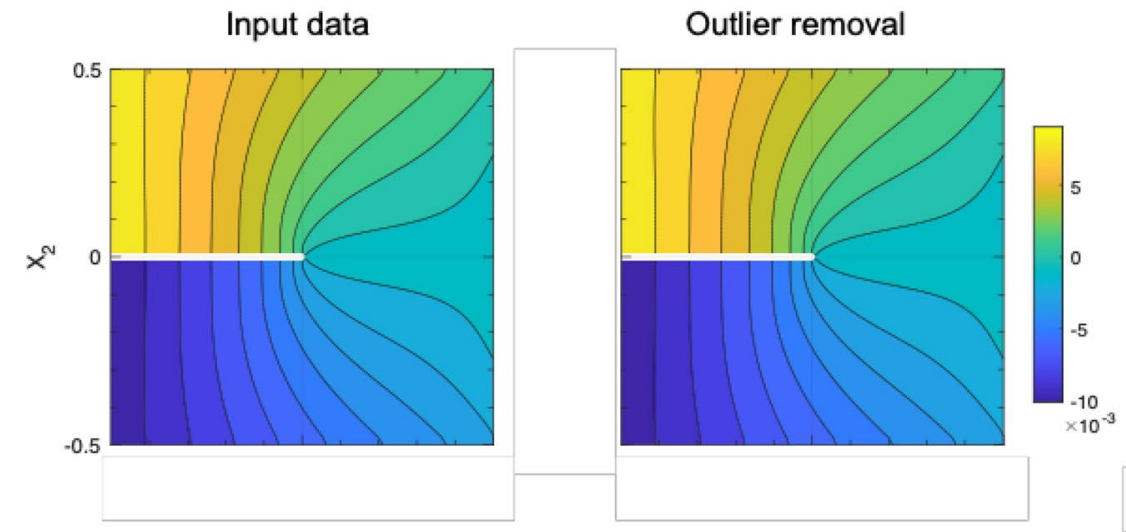

Outliers
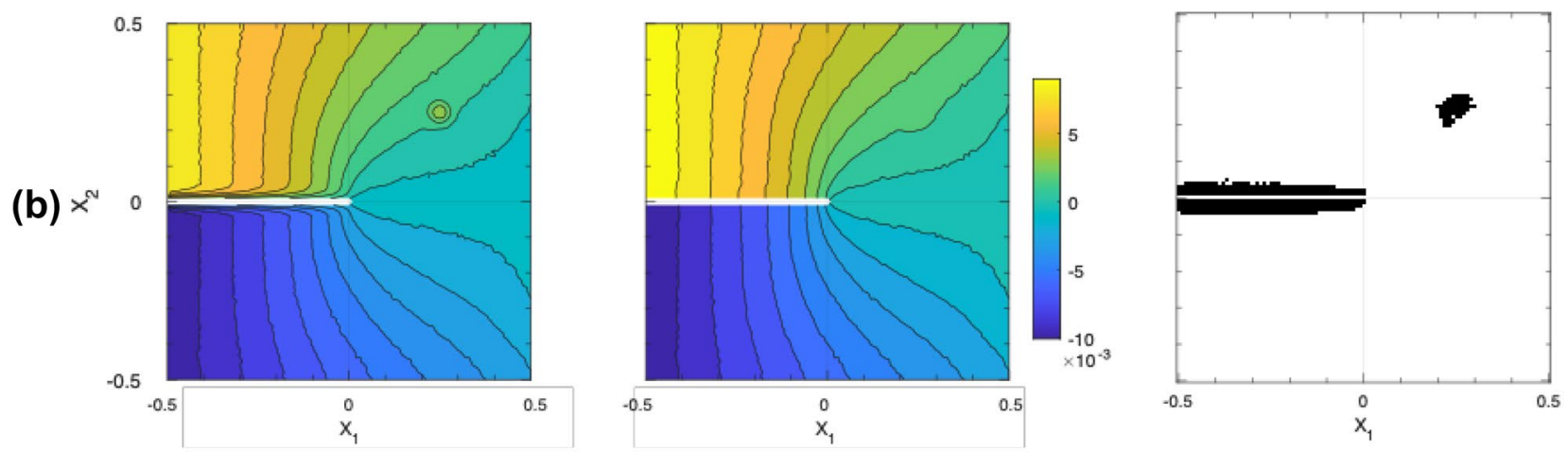

Publisher's Note Springer Nature remains neutral with regard to jurisdictional claims in published maps and institutional affiliations. 